\title{
BMJ Open Combined early and adult life risk factor associations for mid-life obesity in a prospective birth cohort: assessing potential public health impact
}

\author{
Snehal M Pinto Pereira, Karin van Veldhoven, Leah Li, Chris Power
}

To cite: Pinto Pereira SM, van Veldhoven K, Li L, et al. Combined early and adult life risk factor associations for mid-life obesity in a prospective birth cohort: assessing potential public health impact. BMJ Open 2016;6:e011044.

doi:10.1136/bmjopen-2016011044

- Prepublication history and additional material is available. To view please visit the journal (http://dx.doi.org/ 10.1136/bmjopen-2016011044).

SMPP and KvV contributed equally.

Received 5 January 2016 Revised 2 March 2016 Accepted 7 March 2016

\section{CrossMark}

Department of Population, Policy and Practice, Institute of Child Health, University College London, London, UK

Correspondence to Professor Chris Power; christine.power@ucl.ac.uk

\section{ABSTRACT}

Objective: The combined effect of life-course influences on obesity development and thus their potential public health impact is unclear. We evaluated combined associations and predicted probabilities for early and adult life risk factors with central and general obesity in mid-adulthood.

Setting: 1958 British birth cohort.

Participants: 4629 males and 4670 females with data on waist circumference.

Outcome measures: 45 year obesity measured via waist circumference, waist-hip ratio (WHR) and BMI.

Results: At 45 years, approximately a third of the population were centrally obese and a quarter were generally obese. Three factors (parental overweight, maternal smoking during pregnancy and adult inactivity) were consistently associated with central and general obesity. Predicted probabilities for waist obesity increased from those with none to all three risk factors (0.15-0.33 in men; 0.19-0.39 in women $\left.\left(p_{\text {trend }}<0.001\right)\right)$, with a similar trend for general obesity. Additional factors (adult smoking, low fibre and heavy alcohol consumption) were associated with WHR obesity, although varying by gender. Prevalence of risk factors was higher in manual than non-manual groups: for example, in men $38 \%$ versus $25 \%$, respectively, had $\geq 2$ risk factors for waist and general obesity. Conclusions: Early-life and adult factors that are amenable to change are highly prevalent and accumulate in association with central and general obesity in mid-adulthood. The increase in probabilities for mid-adult obesity associated with cumulative levels of risk factors suggests the potential for public health impact.

\section{INTRODUCTION}

Worldwide, an estimated 2.1 billion people are overweight and obese, and between 1980 and 2013 the prevalence in adults increased from $29 \%$ to $37 \%$ in men, and from $30 \%$ to $38 \%$ in women. ${ }^{1}$ Central obesity, as indicated by waist circumference and waist-hip ratio (WHR) and general obesity, indicated by
Strengths and limitations of this study

- Data were from a large nationwide prospective cohort and included information on several risk factors at different life stages and numerous covariates.

- We studied three accepted and validated indicators of obesity using standardised measurements.

- Sample reductions due to missing information were addressed using multiple imputation.

- A limitation is that most risk factors were self-reported.

body mass index (BMI), have been found to predict morbidity ${ }^{2}$ and mortality. ${ }^{3}{ }^{4}$ Thus, it is important to understand the determinants of central and general obesity. Such determinants are regarded as multilayered, from proximal behaviours affecting energy balance to distal societal drivers that shape the environments in which individuals live. ${ }^{5}$ At the individual level, research that tracks the development of obesity suggests that a broad range of influences operate at different life stages. ${ }^{6-8}$ In early life, factors such as high parental $\mathrm{BMI}^{6}$ and maternal smoking during pregnancy ${ }^{9}$ have been found to be associated with increased adult adiposity; while for adulthood, there has been a focus on modifiable risk behaviours such as physical inactivity, diet, smoking and alcohol consumption. ${ }^{10}$ Unfavourable risk behaviours often cluster within individuals and are more prevalent within disadvantaged socioeconomic groups, ${ }^{11}$ possibly contributing to social differences in obesity prevalence and related disease burden.

Assessing the combined association of risk factors for obesity can indicate the potential public health impact of interventions at a specific life stage, as documented for pregnancy and infancy. ${ }^{7} 1213$ For example, one study of four modifiable early-life risk factors (maternal smoking in pregnancy, gestational 
weight gain, breast feeding and infant sleep duration) reported that higher levels of risk factor accumulation were associated with increased predicted probability of childhood obesity and notably, more than $50 \%$ of the population had $>1$ risk factor. ${ }^{7}{ }^{13}$ While many risk factors for obesity are known, few studies to date have investigated their combined association across different life stages. ${ }^{14}$ Thus, several gaps in knowledge remain, including whether combinations of factors from early and later life have cumulative or synergistic effects, whether factors cluster within the general population or different social groups and whether associations of lifetime factors are similar for central and general obesity. Therefore, in a nationwide birth cohort we aimed to evaluate the single and combined associations of early and adult life risk factors for central and general obesity in mid-adulthood. Further, we assessed the predicted probability of central and general obesity for different combinations of early and adult life risk factors. Finally, we aimed to determine whether early and adult life risk factors for central and general obesity cluster and whether any clustering varied by socioeconomic position (SEP). We focused primarily on factors that are of importance to public health policy because they are amenable to change, rather than a broader range of factors.

\section{METHODS}

\section{Study population}

The 1958 British birth cohort is an ongoing, prospective study of all individuals born in England, Scotland and Wales during first week of March 1958 ( $\mathrm{n}=17$ 638), and an additional 920 immigrants with the same birth week. ${ }^{15}$ Survivors from the total target population $(n=18558)$ were followed up into adulthood and at 45 years, 11971 were invited to a biomedical survey performed by a nurse in the participant's home: 9377 (78.3\%) participated. These respondents were broadly representative of the total surviving cohort. ${ }^{16}$ Informed consent was obtained from participants.

\section{Obesity measures}

Three 45 year obesity outcomes were examined: waist and WHR (markers of central obesity) and BMI (marker of general obesity). Waist and hip circumferences were measured to the nearest millimetre with a body tension tape: waist circumference midway between the lower ribs and iliac crest in the mid-axillary line; hip circumference at the widest part of the body below the waist. Weight was measured to the nearest gram with Tanita solar scales and height to the nearest millimetre with a portable stadiometer with sliding head and base plate and a Frankfort plane card. Nurses were trained to use standardised protocols for all measures. ${ }^{17}$ Waist obesity was defined as a circumference $>102 \mathrm{~cm}$ (men) and $>88 \mathrm{~cm}$ (women) and WHR obesity as WHR $\geq 0.95$ (men) and $\geq 0.85$ (women). General obesity was defined as BMI $\left(\mathrm{kg} / \mathrm{m}^{2}\right) \quad \geq 30 \mathrm{~kg} / \mathrm{m}^{2}$. Additionally, three continuous measures were examined: waist circumference $(\mathrm{cm})$, WHR and BMI $\left(\mathrm{kg} / \mathrm{m}^{2}\right)$.

\section{Lifetime risk factors}

Early life: Parental BMI was calculated from reported maternal prepregnancy weight and height in 1958 and paternal reports in 1969. Maternal weight was recorded in preclassified groups ranging from under 7 stone $(44.5 \mathrm{~kg})$ to over 15 stone $(95.3 \mathrm{~kg})$, paternal weight from 6 stone 4 pounds $(39.9 \mathrm{~kg}$ ) to 19 stone 4 pounds $(122.5 \mathrm{~kg})$; weight was converted to kilograms by assigning a value equivalent to the midpoint of the recorded weight category. Height was recorded to the nearest inch and converted into metres. Parental overweight was defined as having at least one parent with a BMI $\geq 25 \mathrm{~kg} / \mathrm{m}^{2}$. Maternal smoking during pregnancy, defined as $\geq 1$ cigarette/day after the fourth month of pregnancy, was reported at birth.

Adult life: factors were self-reported at 42 years. Leisure-time physical activity frequency was reported using a list of examples such as swimming and going for walks, to aid recall. Inactivity was classified as being active $<1$ /week. ${ }^{18}$ Diet was reported as consumption frequency of several foods, for example, fruit, salad/vegetables, wholemeal bread or rolls and fried food ( $>1 /$ day, 1/day, 3-6 days/week, 1-2 days/week, <1/week, occasionally, never). ${ }^{19}$ Because dietary variables were correlated, for example, $47 \%$ of those consuming wholemeal bread $>1$ /day were also consuming fruit $>1$ /day, we used dietary fibre as a previously identified indicator of diet quality, ${ }^{20}$ classifying 'occasional' or 'never' consumption of wholemeal bread or rolls as 'low fibre'. Alcohol consumption was estimated from participant reports of amount of beer, lager, spirits, wine and other alcoholic drinks consumed in the previous week; heavy drinkers were identified as consuming $>35$ (men) and $>21$ (women) units/week. Smoking status was categorised as ever (current and former) and never.

Covariates were selected a priori based on reports in the literature of associations with adiposity. ${ }^{6} 2122$ Early-life covariates included social class at birth (four categories; from professional/managerial to semiskilled and unskilled manual), birth weight $(\mathrm{kg})$, chronic physical handicap or disabling condition at 7 or 16 years (yes/no), and coordination/hand control problems identified at 7,11 or 16 years (grouped as problems at $0,1,2$ or 3 ages); adult life covariates included educational qualifications by 33 years (five categories: no qualifications to degree level), and paid employment at 42 years (yes/no).

\section{Data analysis}

We used logistic regression to investigate risk factor associations with central (waist and WHR) and general obesity and tested whether associations differed by gender using an interaction term; any interactions found were included in subsequent analyses. For our first aim, 
to evaluate the single and cumulative associations of early and adult life risk factors with obesity, we examined each factor and 45 year obesity in three stages: (1) separately,

(2) adjusted for all other early and adult life factors and (3) additionally adjusted for early and adult life covariates. To assess whether risk factors remaining in fully adjusted models for central and general obesity had synergistic effects (on an additive scale), we tested all two-way interactions between risk factors. In supplementary analyses, the above analysis was repeated using linear regression for waist circumference, WHR (multiplied by 100 ) and BMI as continuous variables.

For our second aim, we estimated predicted probabilities and 95\% CIs of obesity, from logistic regression models. Using factors associated with obesity identified from analyses for aim one, we estimated probabilities for cumulative levels of early and adult life risk factors (ie, $0,1,2$ factors, etc). Predicted probabilities of obesity for each level of cumulative risk factors were gender specific and conditioned on covariates, that is, estimated for an individual with a mean birth weight, a father in professional/managerial class at birth, no chronic physical disability or coordination/hand control problems in childhood, degree level qualifications and in paid employment at 42 years.

Finally, we aimed to determine whether early and adult life risk factors for central and general obesity cluster (ie, risk factors have a greater co-occurrence than would be predicted from probability rules, ${ }^{23}$ implying an underlying association between them) and whether any clustering varied by SEP. Using the observed prevalence of single risk factors, we calculated the expected prevalence for each level of cumulative risk factors under the assumption that each risk factor occurred independently of others. For example, the expected prevalence of having none of three risk factors was calculated as the probability of not having risk factor (NRF) 1,2 and 3, that is, NRF $1 \times N R F 2 \times N R F 3$ multiplied by 100 . The observed prevalence was divided by the expected prevalence to give an observed-to-expected $(\mathrm{O} / \mathrm{E})$ ratio; values $>1$ represent a higher prevalence than expected, while values $<1$ represent a lower than expected prevalence. Expected prevalence and $\mathrm{O} / \mathrm{E}$ ratios were calculated for manual and non-manual social groups (class at birth).

Of 9377 participants at 45 years, our analysis was based on 9299 who had information on waist circumference (4629 males and 4670 females). Because of missing data for covariates (ranging from 3\% for class at birth to $30 \%$ for chronic physical disability at 16 years), all model factors were imputed using multiple imputation by chained equations. Imputation models included all model factors and covariates as well as previously identified key predictors of missingness, including childhood internalising and externalising behaviours and cognition. ${ }^{16}$ The dataset was imputed 10 times according to current guidelines. ${ }^{24}$ Non-imputed and imputed associations were similar, hence imputed results are presented. Analyses were performed using STATA V.12.

\section{RESULTS}

At 45 years, $33 \%$ of men and $37 \%$ of women were centrally obese as defined by waist circumference, whereas $34 \%$ of men and $25 \%$ of women were centrally obese as defined by WHR. About a quarter of both genders were identified as having general obesity (table 1 ). Adiposity measures were correlated, most strongly for BMI and waist circumference ( $\mathrm{r}=0.88$ in men; 0.90 in women), while for BMI and WHR correlations were 0.60 (men) and 0.43 (women) and that for waist and WHR were 0.80 (men) and 0.71 (women).

In gender-adjusted and fully adjusted models, parental overweight, maternal smoking in pregnancy and adult inactivity were related to all obesity outcomes. For example, parental overweight was associated with an elevated $\mathrm{OR}\left(\mathrm{OR}_{\mathrm{adjusted}}\right)$ of 1.62 (1.45 to 1.81$), 1.38$ (1.24 to 1.53 ) and 1.80 (1.61 to 2.02 ), respectively, for waist, WHR and general obesity (table 2). Additional associations were identified for central obesity, and for WHR obesity gender differences were observed: in genderadjusted models, smoking and low fibre consumption were related to waist and WHR obesity, and in women heavy drinking was associated with WHR obesity. In fully adjusted models, these associations were abolished for waist obesity, but remained, although attenuated, for WHR obesity. No two-way interactions were observed between parental overweight, maternal smoking in pregnancy and adult inactivity for central or general obesity, suggesting that associations were cumulative rather than synergistic ( $p_{\text {two-way interactions }} \geq 0.38$ in all models, data not shown). Parallel analyses for continuous adiposity measures showed broadly consistent patterns. For example, in adjusted analysis, parental overweight was associated with a $3.19 \mathrm{~cm}$ (2.63 to 3.74) larger mean waist, 0.91 (0.63 to 1.19$)$ greater WHR $(\times 100)$ and $1.60 \mathrm{~kg} / \mathrm{m}^{2}$ (1.37 to 1.83 ) higher mean BMI (see online supplementary table $\mathrm{S} 1$ ).

Only $21 \%$ of the population had no risk factors for waist and general obesity, while $6 \%$ had all three risk factors (table 3). For WHR obesity, 14\% of men and 9\% of women had no risk factors, while $3 \%$ and $14 \%$, respectively, had all risk factors. There was a graded increase in predicted probability of obesity, conditional on covariates, with increasing number of factors (figure 1, $\mathrm{p}_{\text {trend log-odds }}<0.001$ for all models). For example, among men the probability of waist obesity increased from 0.15 to 0.33 ( 0 to 3 risk factors). Risk factors were more prevalent in manual than non-manual groups $\left(\mathrm{p}_{\chi^{2} \text { test }}<0.01\right.$; table 3$)$. For example, in men, $7 \%$ and $3 \%$, respectively, in manual and non-manual groups had all three risk factors for waist and general obesity, while $31 \%$ and $22 \%$, respectively, had two risk factors. With respect to associations between risk factors, the $\mathrm{O} / \mathrm{E}$ ratio was close to 1 for all combinations of risk factors for waist and general obesity indicating that there was no evidence of clustering. For WHR obesity, the O/E ratio was $>1$ for the extreme groups of none and all risk factors, similarly across social groups. 
Table 1 Early life and adult characteristics of men and women in the 1958 birth cohort

Men $(n=4629)^{\star}$
Per cent $(n) /$ Mean (SD)

\begin{tabular}{|c|c|}
\hline \multicolumn{2}{|l|}{45 years obesity } \\
\hline Waist circumference $(\mathrm{cm})$ & 98.5 (11.2) \\
\hline Waist obesity $\dagger$ & 32.5 (1503) \\
\hline Waist-hip ratio (WHR) & $0.9(0.1)$ \\
\hline WHR obesity $\ddagger$ & $34.0(1572)$ \\
\hline Body mass index (BMl; kg/m²) & $27.8(4.3)$ \\
\hline General obesity§ & $25.3(1168)$ \\
\hline \multicolumn{2}{|l|}{ Early life risk factors } \\
\hline Parental overweight $\rrbracket$ & $53.0(1815)$ \\
\hline Maternal smoking in pregnancy & $31.4(1361)$ \\
\hline \multicolumn{2}{|l|}{42 years adult risk factors } \\
\hline Ever smoker** & $53.1(2366)$ \\
\hline Heavy drinkert† & 20.7 (924) \\
\hline 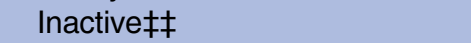 & $33.4(1491)$ \\
\hline Low fibre consumption§§ & $37.3(1663)$ \\
\hline
\end{tabular}

$85.6(12.9)$

$36.7(1715)$

$0.8(0.1)$

$25.1(1174)$

$27.0(5.6)$

$23.6(1098)$

$53.9(1849)$

$32.8(1434)$

$51.3(2327)$

$6.5(297)$

$34.4(1560)$

$33.5(1521)$

${ }^{\star}$ Number of participants with a waist circumference measure. $\mathrm{N}$ varies for each characteristic due to missing data.

$\dagger>102 \mathrm{~cm}$ (men), $>88 \mathrm{~cm}$ (women).

$\ddagger \geq 0.95$ (men), $\geq 0.85$ (women).

$\S \mathrm{BMl} \geq 30 \mathrm{~kg} / \mathrm{m}^{2}$.

ПAt least one parent with $\mathrm{BMI} \geq 25 \mathrm{~kg} / \mathrm{m}^{2}$.

${ }^{* *}$ Current and former smokers.

$\dagger †>35$ (men), >21 (women) units/week.

$\ddagger \ddagger$ Active $<1$ /week.

$\S \S W h o l e m e a l$ bread or rolls eaten 'never' or 'occasionally'.

\section{DISCUSSION}

By mid-adulthood, about a quarter of 1958 British birth cohort members were generally obese and a third were centrally obese. In this general population sample, we identified four important findings. First, we showed that early-life and adult factors accumulate in association with central and general obesity: the more risk factors that were present, the higher the probability of mid-life obesity. For example, the probabilities for general obesity ranged from $9 \%$ to $24 \%$ for 0 to 3 risk factors in women. Second, a substantial proportion of the population had multiple risk factors, for example, $36 \%$ of women had $\geq 2$ risk factors for waist and general obesity. This is important because the risk factors under consideration are amenable to change. Third, we found that the same three factors, namely parental overweight, maternal smoking in pregnancy and adult physical inactivity were associated consistently and independently with central and general obesity. Interestingly, additional adult risk factors were associated with WHR obesity. Fourth, multiple risk factors were more prevalent among manual than non-manual social groups, but clustering did not vary by social class.

\section{Methodological considerations}

Study strengths include the prospective design, large nationwide sample, multiple risk factors and numerous covariates available throughout life. We used three accepted and validated indicators of obesity that were based on standardised measurements. Adult risk factors examined covered main factors in the literature on lifestyles associated with obesity. ${ }^{10}$ However, limitations are acknowledged. Risk factors were self-reported. Maternal smoking was assessed after the fourth month of pregnancy as, at the time, it was thought to exert a greater effect on birth weight in the later stages of pregnancy. ${ }^{25}$ Unlike previous studies of risk factor combinations and obesity in childhood, ${ }^{7} 1213$ we did not include infant feeding method because recent literature suggests that its association with obesity may be due to confounding. ${ }^{26-28}$ For adult physical activity, no information was available on duration and intensity; however our cut-off of active $<1 /$ week has been shown to be associated with adverse health outcomes. ${ }^{29-31}$ Our simple dietary indicator does not capture all dimensions of diet. Yet, simple indicators have advantages in large studies because they are less intrusive, intensive and expensive than other methods. Dietary fibre is a key indicator of diet quality ${ }^{20}$ and was associated in our study with other dietary components including salad, fruit and fried food consumption. While we examined prenatal, early-life and adult risk factors, other life stages such as adolescence were not considered. The sample size was predefined, but as previously demonstrated the study was adequately powered to detect several of the associations of interest (eg, for maternal smoking in pregnancy ${ }^{9}$ and parental overweight ${ }^{32}$ ), although it may be less well powered to detect small effects. As with any observational study, we cannot rule out the possibility that risk factor associations are not causal, for example, associations for adult factors may be due to reverse causation. Finally, sample attrition and missing data on covariates could potentially 
Table 2 Association (OR $(95 \% \mathrm{Cl})$ ) of early-life and adult risk factors with waist, WHR and general obesity at 45 years of age $(\mathrm{n}=9299)$

\begin{tabular}{|c|c|c|c|c|c|c|c|c|}
\hline \multicolumn{3}{|l|}{$\begin{array}{l}\text { Waist obesity* } \\
\text { OR }(95 \% \mathrm{CI})\end{array}$} & \multicolumn{3}{|l|}{$\begin{array}{l}\text { WHR obesity } \\
\text { OR }(95 \% \mathrm{Cl})\end{array}$} & \multicolumn{3}{|c|}{$\begin{array}{l}\text { General obesity* } \\
\text { OR }(95 \% \mathrm{Cl})\end{array}$} \\
\hline $\begin{array}{l}\text { Adjusted for } \\
\text { gender } †\end{array}$ & $\begin{array}{l}\text { Mutually } \\
\text { adjusted }\end{array}$ & Fully adjusted§ & $\begin{array}{l}\text { Adjusted for } \\
\text { gender or } \\
\text { gender specifict }\end{array}$ & $\begin{array}{l}\text { Mutually } \\
\text { adjusted } \ddagger\end{array}$ & Fully adjusted§ & $\begin{array}{l}\text { Adjusted for } \\
\text { gender† }\end{array}$ & $\begin{array}{l}\text { Mutually } \\
\text { adjusted‡ }\end{array}$ & Fully adjusted§ \\
\hline
\end{tabular}

\section{Early life factors}

Parental

overweight

Maternal

smoking in

pregnancy

Adult factors

Smokingl

(M)

(W)

1.71 (1.54 to 1.90$) 1.72$ (1.54 to 1.91$) 1.62$ (1.45 to 1.81$) 1.47$ (1.32 to 1.63$) 1.46$ (1.32 to 1.62$) 1.38$ (1.24 to 1.53$) 1.91$ (1.70 to 2.13$) 1.92$ (1.71 to 2.15$) 1.80$ (1.61 to 2.02$)$

1.31 (1.19 to 1.44$) 1.31$ (1.18 to 1.44$) 1.28$ (1.15 to 1.41$) 1.32$ (1.20 to 1.46$) 1.30$ (1.17 to 1.44$) 1.21$ (1.09 to 1.34$) 1.38(1.24$ to 1.53$) 1.38$ (1.25 to 1.54$) 1.32$ (1.19 to 1.47$)$

Heavy drinkingfl 1.02 (0.90 to 1.16$) 0.99$ (0.87 to 1.14$) 1.01$ (0.88 to 1.15$) 1.11$ (0.95 to 1.29$) 1.04$ (0.89 to 1.22$) 1.05$ (0.89 to 1.23$) 0.88$ (0.76 to 1.01$) 0.86(0.74$ to 0.99$) 0.86(0.74$ to 1.00$)$ (M)

(W) $\quad 1.49$ (1.16 to 1.92$) 1.35$ (1.04 to 1.74$) 1.43$ (1.10 to 1.86$)$

Inactivity $\quad 1.45(1.33$ to 1.59$) 1.42(1.29$ to 1.56$) 1.37(1.25$ to 1.51$) 1.70(1.50$ to 1.94$) 1.63$ (1.43 to 1.85$) 1.55(1.36$ to 1.77$) 1.42(1.28$ to 1.57$) 1.39(1.26$ to 1.54$) 1.34(1.21$ to 1.49$)$

(M)

(W)

1.31 (1.14 to 1.51$) 1.21$ (1.05 to 1.40$) 1.17(1.01$ to 1.35$)$

Low fibre

consumptionๆ

*See definitions in table 1.

†No gender interactions for waist or general obesity; for WHR obesity gender specific for smoking ( $\left.p_{\text {interaction }}=0.02\right)$, heavy drinking $\left(p_{\text {interaction }}=0.046\right)$ and inactivity $\left(p_{\text {interaction }}=0.01\right)$.

¥Adjusted for all early-life and adult risk factors.

$\S$ Adjusted for all early-life and adult risk factors plus early life (class at birth, birth weight, disability at 7/16 years, hand control/coordination problem at $7,11,16$ years) and adult (education at

33 years, employment status at 42 years) covariates.

ๆGenders combined in all gender-adjusted analyses (ie, where no gender interactions were found).

$\mathrm{M}$, men; W, women. 
Table 3 Observed and expected ${ }^{*}$ prevalence of risk factors of waist, WHR and general obesity by social class at birth $†$

\begin{tabular}{|c|c|c|c|c|c|c|c|c|c|}
\hline \multirow{2}{*}{$\begin{array}{l}\text { Number of } \\
\text { risk factors } \neq\end{array}$} & \multicolumn{3}{|l|}{ Total } & \multicolumn{3}{|l|}{ Manual } & \multicolumn{3}{|l|}{ Non-manual } \\
\hline & Observed (\%) & Expected (\%) & O/E & Observed (\%) & Expected (\%) & O/E & Observed (\%) & Expected (\%) & O/E \\
\hline \multicolumn{10}{|c|}{ Waist and general obesity } \\
\hline \multicolumn{10}{|c|}{ Men } \\
\hline 0 & 20.9 & 20.9 & 1.0 & 17.8 & 18.3 & 1.0 & 28.1 & 28.2 & 1.0 \\
\hline 1 & 45.0 & 44.8 & 1.0 & 44.3 & 43.5 & 1.0 & 46.8 & 46.5 & 1.0 \\
\hline 2 & 28.3 & 28.6 & 1.0 & 31.1 & 31.2 & 1.0 & 21.6 & 22.1 & 1.0 \\
\hline 3 & 5.8 & 5.7 & 1.0 & 6.9 & 7.0 & 1.0 & 3.4 & 3.2 & 1.1 \\
\hline \multicolumn{10}{|l|}{ Women } \\
\hline 0 & 20.6 & 20.2 & 1.0 & 17.1 & 17.2 & 1.0 & 29.5 & 28.9 & 1.0 \\
\hline 1 & 43.7 & 44.3 & 1.0 & 43.5 & 43.2 & 1.0 & 44.3 & 45.5 & 1.0 \\
\hline 2 & 29.4 & 29.4 & 1.0 & 31.9 & 32.1 & 1.0 & 22.8 & 22.2 & 1.0 \\
\hline 3 & 6.3 & 6.1 & 1.0 & 7.5 & 7.5 & 1.0 & 3.4 & 3.4 & 1.0 \\
\hline \multicolumn{10}{|l|}{ WHR obesity } \\
\hline \multicolumn{10}{|l|}{ Men } \\
\hline 0 & 14.3 & 13.1 & 1.1 & 11.7 & 10.8 & 1.1 & 20.6 & 20.0 & 1.0 \\
\hline 1 & 35.3 & 35.9 & 1.0 & 32.9 & 33.1 & 1.0 & 40.9 & 41.2 & 1.0 \\
\hline 2 & 33.0 & 34.6 & 1.0 & 34.9 & 36.3 & 1.0 & 28.7 & 29.2 & 1.0 \\
\hline 3 & 14.4 & 14.3 & 1.0 & 17.0 & 17.0 & 1.0 & 8.2 & 8.7 & 1.0 \\
\hline 4 & 3.0 & 2.1 & 1.4 & 3.7 & 2.9 & 1.3 & 1.5 & 0.9 & 1.7 \\
\hline \multicolumn{10}{|l|}{ Women } \\
\hline 0 & 8.6 & 6.1 & 1.4 & 6.8 & 4.7 & 1.4 & 13.3 & 10.7 & 1.2 \\
\hline 1 & 23.0 & 23.3 & 1.0 & 20.9 & 20.4 & 1.0 & 28.3 & 30.5 & 0.9 \\
\hline 2 & 31.7 & 34.6 & 0.9 & 31.2 & 34.0 & 0.9 & 33.1 & 34.0 & 1.0 \\
\hline 3 & 23.2 & 25.2 & 0.9 & 25.4 & 27.5 & 0.9 & 17.7 & 18.8 & 0.9 \\
\hline $4+$ & 13.5 & 11.0 & 1.2 & 15.8 & 13.5 & 1.2 & 7.6 & 6.1 & 1.3 \\
\hline
\end{tabular}

${ }^{*}$ Expected prevalence under the assumption that risk factors occur independently of each other.

†Social class at birth grouped as non-manual (professional, managerial and other non-manual) and manual (skilled, semi and unskilled). †Risk factors are: parental overweight, maternal smoking in pregnancy and adult inactivity (waist and general obesity); parental overweight, maternal smoking in pregnancy, adult inactivity, low fibre consumption (men, WHR obesity); parental overweight, maternal smoking in pregnancy, adult inactivity, low fibre consumption, smoking and heavy drinking (women, WHR obesity).

M, men; W, women; WHR, waist-hip ratio.

lead to bias. As reported elsewhere for the 1958 cohort, there was some under-representation of childhood cognitive and behavioural problems among participants at 45 years, although those remaining in the study were broadly representative of the original cohort. ${ }^{16}$ We avoided sample reductions due to missing information by using multiple imputation following current guidelines. ${ }^{24}$

\section{Interpretation and comparison with other studies}

The intention of our study was to focus on factors that potentially could be modified, rather than to build a prediction model of all possible factors associated with adult obesity. To the best of our knowledge, our study is novel in taking the life course perspective further than previous studies of combined modifiable factors ${ }^{7} 1213$ through its incorporation of early-life and adult factors simultaneously for mid-life obesity. In this regard, three risk factors spanning early life and adulthood were found to be consistently associated with central and general obesity. The three-factor associations were cumulative with no evidence of synergistic effects. One other study of life-time influences on adult adiposity (31 year BMI) showed similar findings to ours, of independent associations for parental (maternal) BMI and own physical activity, but not for smoking or alcohol. ${ }^{14}$ Our results confirm previous findings that early-life factors such as parental overweight and maternal smoking in pregnancy, and adult factors such as physical inactivity are associated with adult adiposity. ${ }^{6} 91033$ However, we extend previous work by demonstrating an additive effect of lifetime risk factors for mid-life obesity. Interestingly, we found more risk factor associations for WHR obesity, including adult smoking, low fibre and alcohol consumption than for waist or general obesity. Some differences in risk factor associations might be expected, given that WHR is less strongly related to BMI than waist circumference, particularly in women, and is a more specific index of fat distribution. ${ }^{3}$ Such observations, may in part, explain why we found additional risk factors for WHR obesity and may also account for some of the gender differences observed for this outcome. Our study is novel in addressing a gap in knowledge of the lifetime factors associated with adult WHR obesity and by identifying additional and overlapping factors when compared to general and waist obesity. Some associations (for smoking and heavy drinking) were stronger for women, although explanations for such gender differences are unknown.

Studying the combined effect of risk factors on obesity provides insights into the potential benefit of changing 

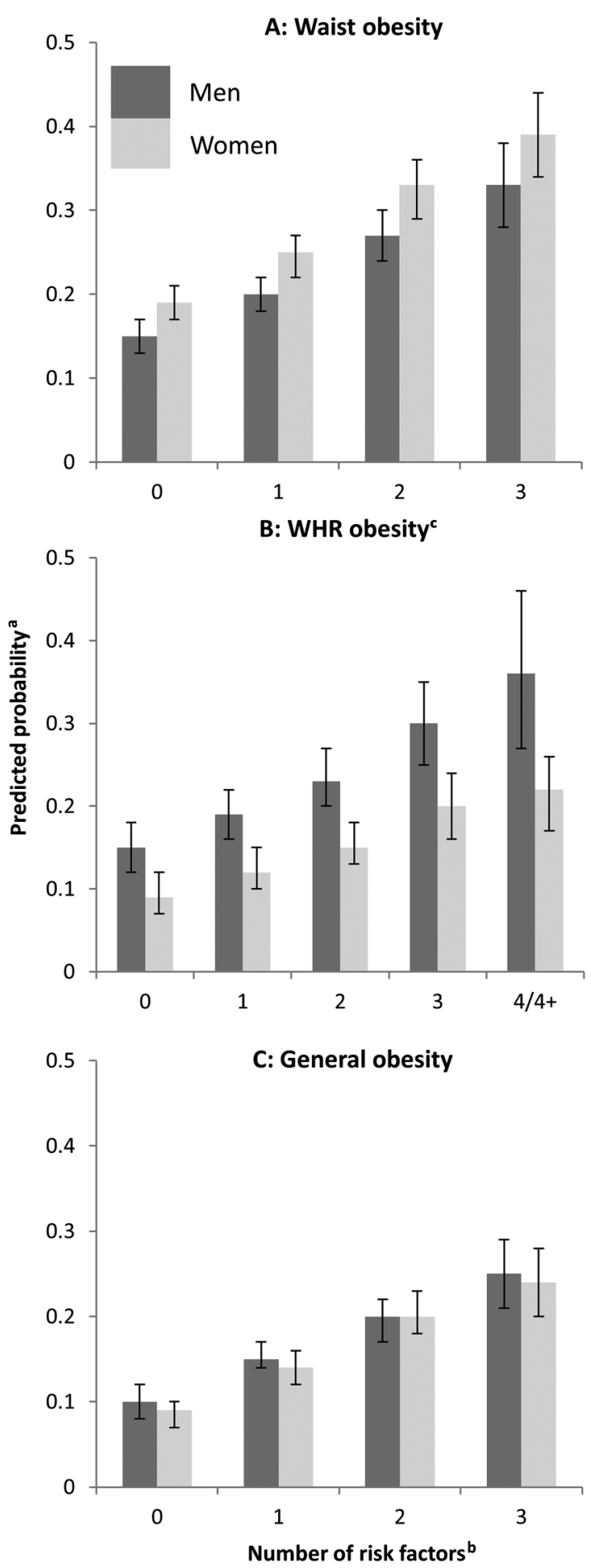

Figure 1 Predicted probability ${ }^{a}$ for obesity by number of risk factors ${ }^{\mathrm{b}}$. ${ }^{\mathrm{P}}$ Probabilities are gender specific, estimated for an individual with a mean birth weight, a father in professional/ managerial class at birth, no chronic physical disability or coordination/hand control problems in childhood, degree level qualifications and in paid employment at 42 years. ${ }^{\text {b Risk factors }}$ are: parental overweight, maternal smoking in pregnancy and adult inactivity (waist and general obesity); parental overweight, maternal smoking in pregnancy, adult inactivity, low fibre consumption (men, WHR obesity); parental overweight, maternal smoking in pregnancy, adult inactivity, low fibre consumption, smoking and heavy drinking (women, WHR obesity). ${ }^{\circ}$ Gender-specific models fitted for WHR obesity. not just one, but multiple factors. A recent meta-analysis showed that a higher number of risk factors was related to a greater risk of mortality, ${ }^{34}$ and our demonstration of multiple risk factors for adult obesity is relevant in this regard, given that obesity is an intermediate phenotype for chronic disease and mortality. A limited number of studies of multiple risk factors for adult obesity report predicted probabilities for adult factors let alone for factors from different life stages. Our findings of a substantial range in predicted probabilities of obesity is consistent with previous observations. ${ }^{75}$ In one study of early life, predicted probabilities for childhood obesity ranged from 0.06 , for those without any of four factors including maternal smoking in pregnancy, to 0.29 with adverse levels for all four. ${ }^{7}$ While others found that, for example, given parents with a BMI of $30 \mathrm{~kg} / \mathrm{m}^{2}$, the probability of childhood obesity ranged from 0.03 to 0.43 with combinations of other factors (eg, gestational smoking and birth weight). ${ }^{35}$ Our findings on probabilities for obesity decades later in mid-adulthood highlight the continuing relevance of early-life factors for later outcomes. Interestingly, we found that lifetime risk factors for central and general obesity did not cluster, although risk factors were more prevalent for those from manual backgrounds: for example, $38 \%$ of men with $\geq 2$ factors for general obesity versus $25 \%$ in non-manual classes. This finding agrees with the limited evidence to date of socioeconomic disadvantage associations with multiple unfavourable behaviours. ${ }^{11}$

\section{Conclusions and implications}

Three risk factors amenable to change, namely parental overweight, maternal smoking in pregnancy and adult leisure-time inactivity, had independent associations with mid-life obesity. The associations observed, spanning prenatal, early-life and adult factors, suggest that public health programmes that aim to reduce the burden of obesity could target a range of factors over the life course. Some of the factors identified are already the focus of public health interventions and our results provide further support for these. The predicted probabilities for cumulative levels of risk factors illustrate the reductions in obesity prevalence, at the population level, that could potentially be achieved with improvement in one or more of these factors. While, at the individual level, the risk factors identified could be used to identify those for whom interventions may be most beneficial. Only $21 \%$ had none of these three risk factors for general obesity and prevalence of $\geq 2$ risk factors was common $(35 \%)$ suggesting that obesity-related health benefits of prevention would apply to substantial proportions of the population. Moreover, the higher rate of risk factor prevalence in manual social groups highlights a possible role in social inequalities in adult obesity and associated health burden and may therefore be relevant to the reduction of social inequalities. This study provides support for strategies to reduce multiple risk factors for the prevention of obesity for current and 
future generations. Our study is of a particular generation and future studies are needed to establish whether the influence of the factors identified apply within the context of changing demographic characteristics. Nonetheless, our results are likely to have continuing relevance to younger generations who remain exposed to high levels of parental overweight, maternal smoking in pregnancy and inactive lifestyles.

Acknowledgements The authors are grateful to the Centre for Longitudinal Studies (CLS), UCL Institute of Education for the use of these data and to the UK Data Service for making them available. However, neither CLS nor the UK Data Service bear any responsibility for the analysis or interpretation of these data.

Contributors All authors designed and conducted the research; SMPP and KvV performed statistical analysis; SMPP, KvV and CP wrote the paper; CP had primary responsibility for final content. All authors read and approved the final manuscript

Funding This research was funded by the Department of Health Policy Research Programme through the Public Health Research Consortium (PHRC) and supported by the National Institute for Health Research Biomedical Research Centre at Great Ormond Street Hospital for Children NHS Foundation Trust and University College London. The views expressed in the publication are those of the authors and not necessarily those of the Department of Health. Information about the wider programme of the PHRC is available from http://phrc.Ishtm.ac.uk. The funders had no input into study design; data collection, analysis, and interpretation; in the writing of the report; and in the decision to submit the article for publication. Researchers were independent of influence from study funders.

Competing interests None declared.

Patient consent Obtained.

Ethics approval Ethical approval for the 45 years surveywas given by South East MREC (ref: 01/1/44).

Provenance and peer review Not commissioned; externally peer reviewed.

Data sharing statement No additional data are available.

Open Access This is an Open Access article distributed in accordance with the Creative Commons Attribution Non Commercial (CC BY-NC 4.0) license, which permits others to distribute, remix, adapt, build upon this work noncommercially, and license their derivative works on different terms, provided the original work is properly cited and the use is non-commercial. See: http:// creativecommons.org/licenses/by-nc/4.0/

\section{REFERENCES}

1. $\mathrm{Ng} \mathrm{M}$, Fleming $\mathrm{T}$, Robinson $\mathrm{M}$, et al. Global, regional, and national prevalence of overweight and obesity in children and adults during 1980-2013: a systematic analysis for the global burden of disease study 2013. Lancet 2014;384:766-81.

2. Wannamethee SG, Papacosta O, Whincup PH, et al. Assessing prediction of diabetes in older adults using different adiposity measures: a 7 year prospective study in 6,923 older men and women. Diabetologia 2010;53:890-8.

3. Pischon $\mathrm{T}$, Boeing $\mathrm{H}$, Hoffmann $\mathrm{K}$, et al. General and abdominal adiposity and risk of death in Europe. $N$ Engl $J$ Med 2008;359:2105-20.

4. Bigaard J, Tjønneland A, Thomsen BL, et al. Waist circumference, $\mathrm{BMI}$, smoking, and mortality in middle-aged men and women. Obes Res 2003;11:895-903.

5. Swinburn BA, Sacks G, Hall KD, et al. The global obesity pandemic shaped by global drivers and local environments. Lancet 2011;378:804-14.

6. Parsons TJ, Power C, Logan S, et al. Childhood predictors of adult obesity: a systematic review. Int J Obes 1999;23:S1-107.
7. Gillman MW, Rifas-Shiman SL, Kleinman K, et al. Developmental origins of childhood overweight: potential public health impact. Obesity (Silver Spring) 2008;16:1651-6.

8. Butland B, Jebb S, Kopelman P, et al. Foresight tackling obesities: future choices-project report. 2nd edn. London: Government Office for Science, 2007

9. Power $\mathrm{C}$, Jefferis BJMH. Fetal environment and subsequent obesity: a study of maternal smoking. Int J Epidemiol 2002;31:413-19.

10. Mozaffarian D, Hao T, Rimm EB, et al. Changes in diet and lifestyle and long-term weight gain in women and men. $N$ Engl J Med 2011;364:2392-404.

11. Poortinga W. The prevalence and clustering of four major lifestyle risk factors in an English adult population. Prev Med 2007;44:124-8

12. Robinson SM, Crozier SR, Harvey NC, et al. Modifiable early-life risk factors for childhood adiposity and overweight: an analysis of their combined impact and potential for prevention. Am J Clin Nutr 2015;101:368-75.

13. Gillman MW, Ludwig DS. How early should obesity prevention start? N Engl J Med 2013;369:2173-5.

14. Kaakinen $M$, Läärä $E$, Pouta $A$, et al. Life-course analysis of a fat mass and obesity-associated (fto) gene variant and body mass index in the northern Finland birth cohort 1966 using structural equation modeling. Am J Epidemiol 2010;172:653-65.

15. Power C, Elliott J. Cohort profile: 1958 British birth cohort (national child development study). Int J Epidemiol 2006;35:34-41.

16. Atherton K, Fuller E, Shepherd P, et al. Loss and representativeness in a biomedical survey at age 45 years: 1958 British birth cohort. $J$ Epidemiol Community Health 2008;62:216-23.

17. Technical report on the national child development study biomedical survey 2002-2004. Secondary Technical report on the national child development study biomedical survey 2002-2004. http://www.cls. ioe.ac.uk/page.aspx?\&sitesectionid=782\&sitesectiontitle=Technica + Report

18. Pinto Pereira SM, Li L, Power C. Early-life predictors of leisure-time physical inactivity in midadulthood: findings from a prospective British birth cohort. Am J Epidemiol 2014;180:1098-108.

19. Parsons TJ, Power C, Manor O. Longitudinal physical activity and diet patterns in the 1958 British birth cohort. Med Sci Sports Exerc 2006;38:547-54.

20. Biltoft-Jensen A, Fagt S, Groth MV, et al. The intake of saturated fat and dietary fibre: a possible indicator of diet quality. $\mathrm{Br} J$ Nutr 2008;100:624-32

21. Osika W, Montgomery SM. Physical control and coordination in childhood and adult obesity: longitudinal birth cohort study. BMJ 2008;337:a699.

22. Power C, Manor O, Matthews S. Child to adult socioeconomic conditions and obesity in a national cohort. Int $J$ Obes 2003;27:1081-6.

23. Ebrahim S, Montaner D, Lawlor DA. Clustering of risk factors and social class in childhood and adulthood in British women's heart and health study: cross sectional analysis. BMJ 2004;328:861-4.

24. Sterne JA, White IR, Carlin JB, et al. Multiple imputation for missing data in epidemiological and clinical research: potential and pitfalls. BMJ 2009;338:b2393.

25. Butler NR, Alberman ED; National Birthday Trust Fund (Great Britain). Perinatal problems: the second report of the 1958 British perinatal mortality survey under the auspices of The National birthday trust fund. Edinburgh, London: E. \& S. Livingstone, 1969.

26. Casazza K, Fontaine KR, Astrup A, et al. Myths, presumptions, and facts about obesity. N Engl J Med 2013;368:446-54.

27. Martin RM, Patel R, Kramer MS, et al. Effects of promoting longer-term and exclusive breastfeeding on adiposity and insulin-like growth factor-I at age 11.5 years a randomized trial. J Am Med Assoc 2013;309:1005-13.

28. Brion MJA, Lawlor DA, Matijasevich A, et al. What are the causal effects of breastfeeding on iq, obesity and blood pressure? Evidence from comparing high-income with middle-income cohorts. Int $J$ Epidemiol 2011;40:670-80.

29. Hamer M, Stamatakis E, Steptoe A. Dose-response relationship between physical activity and mental health: the scottish health survey. Br J Sports Med 2009;43:1111-14.

30. Brown RE, Riddell MC, Macpherson AK, et al. The association between frequency of physical activity and mortality risk across the adult age span. J Aging Health 2013;25:803-14.

31. Vatten LJ, Nilsen TI, Romundstad PR, et al. Adiposity and physica activity as predictors of cardiovascular mortality. Eur $J$ Cardiovasc Prev Rehabil 2006;13:909-15. 
32. Cooper R, Hyppönen E, Berry D, et al. Associations between parental and offspring adiposity up to midlife: the contribution of adult lifestyle factors in the 1958 British birth cohort study. Am J Clin Nutr 2010;92:946-53.

33. Koupil I, Toivanen P. Social and early-life determinants of overweight and obesity in 18-year-old Swedish men. Int J Obes (Lond) 2008;32:73-81.
34. Loef $\mathrm{M}$, Walach $\mathrm{H}$. The combined effects of healthy lifestyle behaviors on all cause mortality: a systematic review and meta-analysis. Prev Med 2012;55:163-70.

35. Morandi A, Meyre D, Lobbens S, et al. Estimation of newborn risk for child or adolescent obesity: Lessons from longitudinal birth cohorts. Plos ONE 2012;7:e49919. 